\title{
The Analysis of ASEAN Travel Markets to Thailand: An Approach to Promote Thailand's Economy
}

\author{
Aswin Sangpikul \\ Dhurakij Pundit University, Bangkok, Thailand \\ aswin.sal@dpu.ac.th
}

\begin{abstract}
ASEAN travel markets have been one of the important international tourist markets to Thailand. However, little effort has segmented this market for marketing purposes through an empirical study. This study, therefore, has an objective to examine the perception of Thailand's destination attractions of ASEAN travelers to Thailand by using pull factors. The results of pull factors will be employed to segment the possible sub-segments of the ASEAN tourists to Thailand. The results of the study indicate that there are at least two possible subsegments among the ASEAN tourists, and these two are labeled as 1) 'cultural seekers' and 2) 'leisure seekers'. Important implications to promote Thailand's economy by targeting these two sub-segments are discussed.
\end{abstract}

Keywords: pull motivation factor, market segmentation, ASEAN travelers, Thailand

\section{Introduction}

With the rapid growth of tourism industry in Thailand, toady tourism has been regarded as one of the most important tools used to boost economies and promote country's development. The growth of tourism in Southeast Asia has developed very fast and each country is attempting to promote tourism to generate revenues to the countries. Every nation has developed various marketing campaigns to persuade tourists to visit its state by promoting attractive tourist destinations, local culture, food, architecture, folklore and man-made tourist attractions. Thailand, the leading tourism state of the ASEAN, has various major tourist attractions located in different parts of the country both natural and cultural heritages. Due to the continuously increasing tourist arrivals to Thailand, the ASEAN travel markets have become the most important travel market for Thailand's tourism industry. However, little effort has segmented this market for marketing purposes through an empirical study. This study, therefore, has an objective to examine the travel motivations of Asian travelers to Thailand by focusing on the pull motivation factors (or destination attractions). The study employed the pull motivations as a segment tool to identify the possible sub-segments of the ASEAN tourists to Thailand. The results of the study are expected to yield the useful information for destination marketers to develop more appropriate marketing programs to correspond to this market and to promote Thailand's tourism economy.

\section{Methodology}

In this study, the target populations were ASEAN travelers aged 25 years old or over who were traveling in Thailand. The questionnaire was developed from a comprehensive review of previous studies focusing pull motivations [2]-[5]. The questionnaire consisted of two sections: 1) demographic characteristics and 2) pull factors (destination attributes). Measurement of pull factors were ranged from 1 (strongly disagree) to 5 (strongly agree). Using a convenience sampling method, data were collected at major tourist attractions in Bangkok during December 2015, through a closed-ended, self-administered questionnaire. Two hundred and ten questionnaires were obtained as a partial research paper of a larger project. Descriptive statistics were used to provide general information of the respondents while factor analysis was employed to delineate the underlying dimensions that were 
associated with pull factors. Later, the pull factors identified from factor analysis were further used as the variables in cluster analysis which was performed to segment the market into homogeneous groups.

\section{Findings}

Table 1: Socio-demographic profile of respondents

\begin{tabular}{|c|c|c|c|c|}
\hline Socio-demographic variables & Percent (\%) & Socio-demographic variables & & Percent (\%) \\
\hline Gender & & Occupation & & \\
\hline Male & $54 \%$ & Company employee & & $32 \%$ \\
\hline Female & $46 \%$ & Business owner/self-employed & & $22 \%$ \\
\hline Age (mean 37.5 years, S.D. 3.3 years) & & Government sector & $15 \%$ & \\
\hline $25-35$ years $\quad 40 \%$ & & Professionals and technicians & $17 \%$ & \\
\hline $36-45$ years & & Housewife & $10 \%$ & \\
\hline 46 and over & & Unemployment & $3 \%$ & \\
\hline Marital status & & Others & $1 \%$ & \\
\hline Married & & Monthly income (US\$) & & \\
\hline Single & $50 \%$ & Less than $\$ 1,000$ & & $30 \%$ \\
\hline Divorced/widowed & $10 \%$ & $\$ 1,001-2,000$ & & $25 \%$ \\
\hline Education & & $\$ 2,001-3,000$ & & $18 \%$ \\
\hline High school or lower $\quad 10 \%$ & & $\$ 3,001-4,000$ & $15 \%$ & \\
\hline Technical/vocational school1 & $20 \%$ & More than $\$ 4,001$ & & $12 \%$ \\
\hline \multirow[t]{4}{*}{ College degree } & $70 \%$ & Number of visits to Thailand & & \\
\hline & & One time & $68 \%$ & \\
\hline & & Two - three times & $22 \%$ & \\
\hline & & Four times or more & $10 \%$ & \\
\hline
\end{tabular}

Table 1 shows respondents' socio-demographic characteristics. For example, the proportion of male respondents (54\%) was higher than that of females (46.0\%). About $40 \%$ were in the age group between 25-35 years, while 35\% were between 36-45 years, and 25\% were 46 years and over. The majority of the respondents were single $(50 \%)$, and $70 \%$ had education at college level. Among the 210 respondents, they came from different countries such as Malaysia, Singapore, Indonesia, Philippines, and Indo-china countries.

Table 2: Factor analysis of pull factors (destination attractions)

\begin{tabular}{|c|c|c|c|c|c|}
\hline Pull factor dimensions (Cronbach's alpha) & Factor loading & Eigenvalue & Variance explain & led $\mathrm{F}$ & Factor mean \\
\hline Factor 1: Vis attractions (alpha $=0.80)$ & & 2.80 & $32.50 \%$ & & 4.02 \\
\hline Cultural \& historical places & 0.85 & & & & \\
\hline Thai temples & 0.82 & & & & \\
\hline Thai cultures / local way of life & 0.80 & & & & \\
\hline Natural scenery and landscape & 0.74 & & & & \\
\hline Factor 2: Travel arrangements $\&$ facilities $($ alpha $=0.81)$ & 2.14 & & $14.30 \%$ & 3.81 & \\
\hline Convenience of traveling and ease of tour arrangement & 0.87 & & & & \\
\hline Quality of tourist places and facilities & 0.81 & & & & \\
\hline Tour programs offered by tour companies & 0.83 & & & & \\
\hline Reasonable price of goods and services & 0.78 & & & & \\
\hline A variety of tourist attractions & 0.70 & & & & \\
\hline Factor 3: Leisure activities (alpha $=0.78)$ & & 1.30 & $8.20 \%$ & & 3.62 \\
\hline A variety of shopping places & 0.80 & & & & \\
\hline Night life and entertainment & 0.75 & & & & \\
\hline Beach tourism & 0.72 & & & & \\
\hline Thai spa and traditional massage services & 0.67 & & & & \\
\hline Thai food & 0.64 & & & & \\
\hline Friendliness of Thai people & 0.61 & & & & \\
\hline Nature attractions & 0.60 & & & & \\
\hline Factor 4: Safety \& cleanliness $($ alpha $=0.70)$ & 1.29 & & $6.30 \%$ & 3.38 & \\
\hline Safety and security & 0.79 & & & & \\
\hline Hygiene and cleanliness & 0.72 & & & & \\
\hline Total variance explained & $61.30 \%$ & & & & \\
\hline
\end{tabular}


As shown in Table 2, four factor dimensions were derived from the factor analysis of 18 pull motivational items, and were labeled: (1) 'cultural attraction, (2) 'travel arrangement \& activities', (3) 'leisure activities' and (4) 'safety \& cleanliness'. Among them, 'cultural attraction' was considered the most important pull factors attracting the respondents to Thailand with the highest mean score of 4.05. In this study, all the pull factor dimensions had eigenvalues greater than 1.0, and their items had factor loading greater than 0.4.

\section{A Cluster Analysis: Market Segmentation of Asian Travelers to Thailand}

A combination of hierarchical and non-hierarchical cluster analysis was employed to identify market segment of ASEAN travelers based on their perceived pull factors (destination attractions). Through the cluster analysis, two clusters (groups) were determined as appropriate. To delineate the two identified clusters and label them, the mean scores for each pull factor dimension were computed as suggested by previous studies [3]. The results are presented in table 3 . Based on the scores of factor mean in each factor dimension, cluster 1 had the highest mean score on factor 1 'cultural attractions' (mean=4.05) and factor 4 'safety \& cleanliness' (mean=3.36), respectively. This suggests the label of cluster 1 as 'cultural motivations'. For cluster 2, it appears that the segment had the high mean score on factor 2 'travel arrangement \& facilities' $(M=3.79)$ and factor 3 'leisure activities' $(M=3.55)$. Therefore, it is suggested to label cluster 2 as 'leisure motivations'.

Table 3: Mean scores of pull factor dimensions as rated by the two clusters

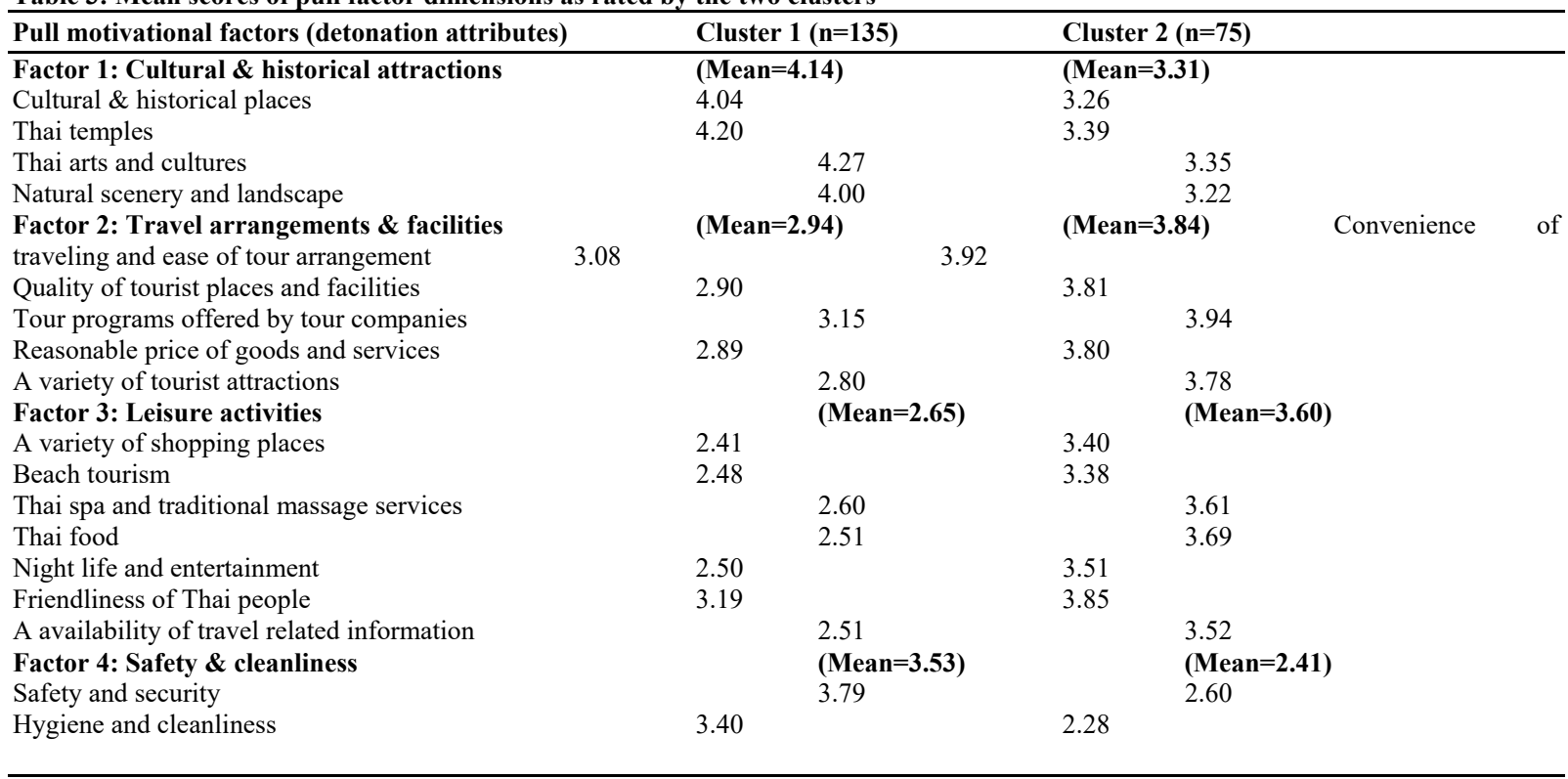

Table 4: Socio-demographic profiles of the two cluster of Asian travelers to Thailand

\begin{tabular}{|c|c|c|c|c|c|}
\hline \multirow{2}{*}{$\begin{array}{l}\text { Socio-demographic characteristics } \\
\text { Gender }\end{array}$} & Cluster $1(\mathrm{n}=135)$ & Cluster $2(n=75)$ & \multirow[t]{2}{*}{$\left(\chi^{2}\right)$} & \multicolumn{2}{|l|}{ Sig. } \\
\hline & & & & 22.57 & $0.02 *$ \\
\hline Male & $47.3 \%$ & $65.2 \%$ & & & \\
\hline Female & $52.7 \%$ & $34.8 \%$ & & & \\
\hline Totals & $100 \%$ & $100 \%$ & & & \\
\hline Age & & & 18.04 & $0.032 *$ & \\
\hline $25-35$ years & $39.4 \%$ & $56.1 \%$ & & & \\
\hline $36-45$ years & $55.5 \%$ & $33.3 \%$ & & & \\
\hline 46 and older & $9.5 \%$ & $10.6 \%$ & & & \\
\hline Totals & $100 \%$ & $100 \%$ & & & \\
\hline Marital status & & & & & \\
\hline Married & $75.5 \%$ & $72.8 \%$ & & 3.04 & 0.865 \\
\hline Single & $8.7 \%$ & $7.8 \%$ & & & \\
\hline Divorced/Separated/Widowed & $15.8 \%$ & $19.4 \%$ & & & \\
\hline Totals & $100 \%$ & $100 \%$ & & & \\
\hline Education & & & 2.03 & 0.731 & \\
\hline High school or lower & $33.9 \%$ & $27.3 \%$ & & & \\
\hline Technical or vocational school & $13.8 \%$ & $15.1 \%$ & & & \\
\hline College/university degree & $52.3 \%$ & $57.6 \%$ & & & \\
\hline Totals & $100 \%$ & $100 \%$ & & & \\
\hline Occupations & & & 20.07 & $0.01 *$ & \\
\hline Company employee & $42.5 \%$ & $24.3 \%$ & & & \\
\hline Business owner/self-employed & $11.4 \%$ & $21.1 \%$ & & & \\
\hline Government officer & $17.7 \%$ & $7.3 \%$ & & & \\
\hline
\end{tabular}


Table 4, cont

\begin{tabular}{|c|c|c|c|c|c|c|c|}
\hline Professionals & $9.5 \%$ & & $12.6 \%$ & & & & \\
\hline Technician & & $5.0 \%$ & & $6.9 \%$ & & & \\
\hline Housewife & $7.3 \%$ & & $10.1 \%$ & & & & \\
\hline Unemployment & $5.2 \%$ & & $3.5 \%$ & & & & \\
\hline Others & $1.4 \%$ & & $2.6 \%$ & & & & \\
\hline Totals & $100 \%$ & & $100 \%$ & & & & \\
\hline Annual Income (US Dollars) & & & & & & 17.59 & $0.038^{*}$ \\
\hline Less than $\$ 1,000$ & $40.4 \%$ & & $24.9 \%$ & & & & \\
\hline$\$ 1,001-2,000$ & $23.8 \%$ & & $30.8 \%$ & & & & \\
\hline$\$ 2,001-3,000$ & $18.1 \%$ & & $27.5 \%$ & & & & \\
\hline$\$ 3,001-4,000$ & $11.8 \%$ & & $13.5 \%$ & & & & \\
\hline More than $\$ 4,001$ & $5.9 \%$ & & $3.3 \%$ & & & & \\
\hline Totals & $100 \%$ & & $100 \%$ & & & & \\
\hline No. of visits to Thailand & & & & & 10.7 & 0.335 & \\
\hline First time & & $64.4 \%$ & & $58.9 \%$ & & & \\
\hline $2^{\text {nd }}-3$ rd times & $30.4 \%$ & & $33.4 \%$ & & & & \\
\hline 4 times or more & $5.2 \%$ & & $7.7 \%$ & & & & \\
\hline Totals & $100 \%$ & & $100 \%$ & & & & \\
\hline
\end{tabular}

Table 4 presents the profile of ASEAN travelers to Thailand (based on each cluster) by a cross-tabulation to provide socio-demographic profiles of the two clusters. Each of the cluster (segment) is discussed as follows.

\section{Cluster 1 (cultural seekers)}

This segment represented $65 \%(n=135)$ of the total samples. It consisted of travelers who demonstrated a strong desire to learn about Thai culture and the history (from table 3 ). They traveled to Thailand to seek new knowledge and experience different culture that they could not obtain from their usual environment. They also concerned about safety and cleanliness when traveling to Thailand. The members of this cluster appeared to place the greatest importance on Thai cultural experience such as Thai arts, the temples, and visiting historical places. More than half $(52.7 \%)$ were female travelers and somewhat older travelers than the members of cluster 2. Most of them were married (75.5\%), and had education level at university degree $(52.3 \%)$. The group members had different occupation backgrounds. However, nearly $42.5 \%$ were business employees and $17.7 \%$ were government officers. The majority of respondents in this cluster had monthly income in the ranges of less than $\$ 1,000$ (40.4\%) and between $\$ 1,001-2,000$ (23.8\%), and about $64 \%$ were the first-time visitors to Thailand.

\section{Cluster 2 (leisure seekers)}

Travelers belonging to this segment represented $35 \%(n=75)$ of the total samples. The members of this cluster were eager to get away from their ordinary environment and busy lives (based on table 3). They tended to enjoy holidays and vacations overseas. They considered Thailand as a good place for overseas vacation with a variety of tourist attractions and reasonable prices of goods and services. They traveled to Thailand to enjoy and experience a variety of leisure and holiday experiences such as Thai food, Thai spa and massage, beautiful beaches, entertainment, night life and shopping activities. The majority of this cluster were male travelers (65.2) and somewhat younger than cluster 1. About 56.1\% were in the age between 25-35 years old. Most of them were married (72.8\%), and had education at the university level (57.6\%). Most of them were still working and had different occupation backgrounds. Nearly $31 \%$ had monthly incomes in the range of $1,001-2,000$, while $27.5 \%$ earned income between $\$ 2,001-3,000$. More than half (58.9\%) were first-time visitors to Thailand. 


\section{Conclusion and Recommendation}

This study identified the two segments of ASEAN travelers to Thailand: 'cultural seekers' and 'leisure seekers'. The result of the current study may be similar to [7] in terms of the perception of Thailand's destination attractions (pull factors) among Asian senior travelers to Thailand due to similar framework. However, the management implication is different based on different target segments and variables. Based on the current results, it indicated that the members of cluster 1 (cultural seekers), the largest segment identified in this study (65\% of the samples), seemed to perceive Thailand's cultural and historical attractions as the major factors drawing them to Thailand. They came to Thailand with the main motivations to see new experience in Thailand. This implication should be useful for destination marketers to match push and pull motivations by highlighting the new experience in cultural tourism/products, particularly for the design of tour packages and marketing programs. Based on this finding, this suggests that cultural and historical attractions of Thailand should be developed as the major theme when marketing this segment (cultural motivations). Major destinations for this group may be cultural-oriented cities, for example, Bangkok, Ayutthaya, northern provinces, and Sukhothai.

As for the cluster 2 (leisure seekers), the majority of this segment was repeat travelers; suggesting that the products offered for this segment should be different from the first group. In particular, their main motivations are to experience new things in Thailand also but are more likely to enjoy holiday and leisure activities. For marketing purposes, there is a need to communicate to the 'leisure motivations' that there are a variety of holiday and leisure activities available in Thailand than a typical package tour. As the members of this segment are likely to prefer products that are different from those in segment one, it is suggested that products offered for this group should be focused on leisure and relaxation activities. Major products for this group may be various such as beach tourism, nature/ecotourism/adventure tourism, sightseeing tours, and sport tourism.

\section{References}

[1] S. Cha, K. McCleary, and M. Uysal. Travel Motivations of Japanese Overseas Travelers: Factors-Cluster Segmentation Approach. Journal of Travel Research Vol. 34(1995), pp. 33-39.

[2] S. Jang and C. Wu. Seniors' travel motivation and the influential factors: An examination $\mathrm{f}$ Taiwanese seniors. Tourism Management 27(2006), pp. 306-316.

[3] S. Jang and L. Cai. Travel motivations and destination choice: A study of British outbound market. Journal of Travel \& Tourism Marketing Vol 13(2002), pp. 111-133.

[4] H. Kaiser. An index of factorial simplicity. Psychologist Vo. 39 (1974), pp. 31-36.

[5] D. Klenosky. The pull of tourism destinations. Journal of Travel Research Vol 40(2002), p. 385-395.

[6] W. Reece. Are senior leisure travelers different? Journal of Travel Research Vol 43(2004), pp. 11-18.

[7] A. Sangpikul and A Batra. A factor-cluster analysis on Thailand's destination attractions. Conference proceeding of the international conference, Fukuoka, Japan, 1-3 February 2015.

[8] E. Sirakaya. M. Uysal, and C. Yoshioka. Segmenting the Japanese tour market to Turkey. Journal of Travel Research Vol 41(2003), pp. 293-304.

[9] J. Teaff and T. Turpin. (1996). Travel and the elderly. Parks and Recreation Vol 31(1996), pp. 16-19.

[10] M. Uysal and C. Jurowski. Testing the push and pull factors. Annals of Tourism Research Vol 21(1994), pp. 844-846. 
[11] X. You and J. O'Leary. Destination behavior of older UK travelers. Tourism Recreation Research Vol 24(1999), pp. 23-34.

[12] X. You, J. O'Leary, A. Morrison, and G. Hong. A cross-cultural comparison of travel push and pull factors: UK vs. Japan. International Journal of Hospitality \& Tourism Administration 5(2000), pp. 35-52.

[13] N. Yavuz, S. Baloglu, and M. Uysal. Market Segmentation of European and Turkish Travelers to North Cypru. International Journal of Tourism and Hospitality Research Vol 9(1998), pp. 4-18.

[14] Y. Yoon and M. Uysal. An Examination of the Effects of Motivational and Satisfaction on Destination Loyalty: A Structural Model. Tourism Management Vol 26 (2005), pp. 45-56. 
